hyperkalaemia in the case reported above. This should be borne in mind in patients with leukaemia who may appear to have hyperkalaemia and it does not carry with it the known dangers of hyperkalaemia in vivo.

\section{Acknowledgement}

I am grateful to Dr James Innes for his permission to publish and his advice in the preparation of this case report.

\section{References}

Bronson, W.R., De Vita, V.T., Carbone, P.P. \& Cotlove, E. (1966) Pseudo-hyperkalemia due to release of potassium from white blood cells during clotting. New England Journal of Medicine, 274, No. 7; 369.

Clain, A. (1973) (Ed.) Hamilton Bailey's Demonstrations of Physical Signs in Clinical Surgery. 15th Edn, p.333. John Wright \& Son Ltd, Bristol.

CoORAY, G.H. (1952) Spontaneous rupture of a leukaemic spleen. British Medical Journal, 1, 693.

FenNelly, J.J., Smyth, H. \& Muldowney, F.P. (1974) Extreme hyperkalaemia due to rapid lysis of leukaemic cells. Lancet, i, 27.

Greenfield, M.M. \& LuND, H. (1944) Spontaneous rupture of the spleen in chronic myeloid leukemia. Ohio Stare Medical Journal, 40, 950.

Hartmann, R.C., Auditore, J.V. \& Jackson, D.P. (1958) Studies on thrombocytosis. I. Hyperkalemia due to release

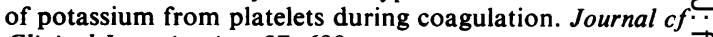
Clinical Investigation, 37, 699.

HyNes, H.E., Silverstein, M.N. \& FAwCETT, K.J. (1964) Spontaneous rupture of the spleen in acute leukemia. Cancer, New York, Philadelphia, etc., 17, 1356.

MacPherson, A.I.S., Richmond, J. \& StUART, A.E. (1972) The Spleen, p. 212. C. C. Thomas, Springfield, Illinois.

MYERSON, R.M. \& Frumin, A.M. (1960) Hyperkalemia $\stackrel{\mathbb{D}}{\Omega}$ associated with myeloproliferative disorder. Archives of Internal Medicine, 106, 479.

NeAL, J.M. (1940) Rupture of spleen in myelogenous leu- $\vec{\circ}$ kemia. Medical Bulletin of the Veterans' Administration, 17, 96.

RinglehanN, B., Laszlo, E. \& Vajda, L. (1974) Pseudohyperkalaemia in acute myeloid leukaemia. Lancet, i, 928. 음

SARIN, L.R. \& SARIN, J.C. (1957) Spontaneous rupture of spleen in chronic myeloid leukaemia. Journal Indian Medical Association, 29, 286.

Tartaglia, A.P., Scharfman, W.B. and Propp, S. (1962). Splenic rupture in leukemia. New England Journal of 8 Medicine, 267, No. 1, 31.

Wills, M.R. \& Fraser, I.D. (1964). Spurious hyperkalaemia. Journal of Clinical Pathology, 17, 649.

\title{
Agranulocytosis and systemic candidiasis following clomipramine therapy
}

\author{
R. L. Souhami \\ M.D., B.Sc., M.R.C.P.
}

\author{
C. R. AshtoN \\ B.M., B.Ch., M.R.C.P.
}

\author{
J. P. LeE-PotTer \\ M.B., M.R.C.Path.
}

Poole General Hospital, Poole, Dorset

\begin{abstract}
Summary
A case of agranulocytosis following clomipramine treatment is described. The period of agranulocytosis lasted for 19 days and was complicated by systemic Candida infection which was successfully treated with flucytosine.
\end{abstract}

\section{Introduction}

Agranulocytosis is a well recognized complication of phenothiazine administration, and these drugs are the most important cause of drug-induced agranulocytosis at the present time. Agranulo-

Correspondence; Dr R. L. Souhami, University College Hospital, Gower Street, London, W.C.1. cytosis has been recorded with imipramine (Miller, 은 1963; Bird, 1960) and desipramine (Crammer and $\supset$ Elkes, 1967). There are no published reports of this complication following clomipramine, but three $N$ cases of clomipramine-induced agranulocytosis have been reported to the makers in the U.K. (Dr G. Beau- $N$ mont, personal communication). Intravenous clomi- స్ pramine is used in the treatment of severe and $\overline{2}$ resistant forms of depression. A case is now reported 0 of severe agranulocytosis occurring in a patient who had received intravenous clomipramine for depression. The illness which followed was complicated by systemic Candida infection which was successfully treated with flucytosine. 
Case report

A 37-year-old woman had suffered from severe depression which had not improved with dothiepin hydrochloride (prothiaden) and ECT. Treatment was started with a regimen of oral and intravenous clomipramine (Anafranil) over a period of 26 days. She received $200 \mathrm{mg} /$ day for 4 days orally and subsequently 50-250 mg i.v./day. A total dose of $2.65 \mathrm{~g}$ was given with clinical improvement.

Three weeks after stopping the treatment she developed a fever and sore throat. A reddened pharynx and cervical lymphadenopathy were noted. She was treated with tetracycline for 1 week, without effect. A white cell count at this time showed a complete absence of neutrophils and she was transferred to the medical wards.

On examination she was severely ill. Temperature, $39.5^{\circ} \mathrm{C}$; pulse, $120 / \mathrm{min}$; blood pressure, $120 / 80 \mathrm{~mm}$ $\mathrm{Hg}$. There was gross oral and pharyngeal Candida infection and cervical lymphadenopathy. There were rales at both lung bases. The liver and spleen were enlarged $2 \mathrm{~cm}$ below the costal margin. Investigations: Hb. $11 \cdot 1 \mathrm{~g} / \mathrm{dl}$, WBC $0.6 \times 10^{9} / 1$ (all lymphocytes). Platelets $424 \times 10^{9} / 1$, ESR $100 \mathrm{~mm} / 1 \mathrm{hr}$. Blood cultures were sterile on all occasions. C. albicans was isolated from mouth, throat and sputum. Chest X-ray showed extensive bilateral pulmonary infiltration. Examination of the sternal marrow gave blood taps with scanty mononuclear cells which were mostly lymphocytes, but there was a complete absence of myeloid and erythroid precursors. Megakaryocytes were present.

Her progress is shown diagrammatically in Fig. 1. She was treated with gentamicin $80 \mathrm{mg} 8$-hourly and clindamycin $300 \mathrm{mg}$ 6-hourly at first and oxymetholone $50 \mathrm{mg}$ 8-hourly was introduced after 4 days. There was a complete lack of response as judged by fever or improvement in chest X-ray appearances. Her condition deteriorated and because of the extensive Candida infection treatment with flucytosine was begun. She was given $2.5 \mathrm{~g}$ i.v. 6-hourly. Over the next 10 days she remained gravely ill, with high fever and mental confusion. There was a complete absence of circulating neutrophils. However, the pulmonary infiltrates regressed to some extent. She became jaundiced with serum bilirubin of 94 $\mu \mathrm{mol} / 1$, SGOT 122 i.u./1, alkaline phosphatase 56 i.u./1 (8 KA u/l). The haemoglobin fell to $9.6 \mathrm{~g} / \mathrm{dl}$ and she was transfused 4 units of blood.

A second marrow examination 10 days after admission gave scanty fragments consisting mostly of fat spaces. Megakaryocytes were present but there was no evidence of regeneration. Just before recovery a leucocyte transfusion was made using fresh whole blood from a patient with myelosclerosis in whom the total leucocyte count was $100 \times 10^{\%} / 1$. This did not appear to confer any benefit and examination of

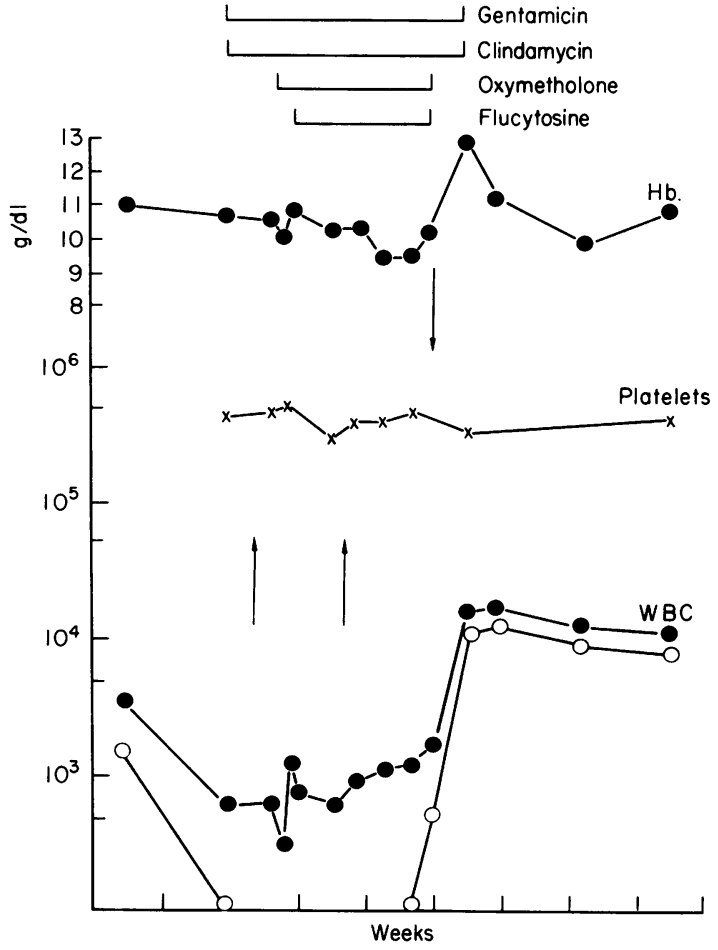

Fig. 1. Showing haematological values with total neutrophil count shown by open circles. Bone marrow examinations indicated by vertical arrows pointing upwards. Blood transfusion indicated by vertical arrows pointing downwards. The observed period of agranulocytosis was 19 days.

the blood $6 \mathrm{hr}$ after transfusion revealed no increase in total leucocyte count and some damaged neutrophils on the blood film.

Twelve days after she had been noted to be neutropenic there was an increase in the lymphocyte count followed by the sudden reappearance of neutrophils, rising to $16 \cdot 0 \times 10^{9} / 1$ over 4 days. There was a simultaneous clinical improvement and the patient was discharged $\mathbf{4 0}$ days after admission. At the time of discharge the pulmonary infiltrates had disappeared.

During the period of agranulocytosis she was fed through a nasogastric tube. After recovery she complained of severe dysphagia and barium swallow revealed an extensive stricture of the oesophagus. This failed to improve on dilatation and 4 months later the lower two-thirds of the oesophagus was resected and a length of colon transplanted. Her swallowing then improved. There was no evidence of Candida infection in the excised oesophagus.

\section{Discussion}

The selective loss of polymorphonuclear leucocytes from the blood was first recognized by Brown 
and Ophuls (1902). Later Madison and Squier (1934) recognized amidopyrine as the offending drug. There appear to be at least two mechanisms of drug induced agranulocytosis (Pisciotta, 1973). The first mechanism appears to be immunological, granulocytes being destroyed peripherally immediately after ingestion of the drug to which the patient is sensitive. The precipitous decline in granulocytes which follows is reversed on stopping the drug. Amidopyrine seems to act in this way.

The second type of reaction is idiosyncratic and can occur after prolonged drug administration. The effect may be related to the total dose administered. There is a sudden onset of neutropenia and the bone marrow reveals complete absence of granulocyte and erythroid precursors. Thrombocytopenia does not occur. Anaemia is not a problem clinically because of the long life of red cells. If the drug is withdrawn and the patient kept alive, the recovery of the blood is sudden and occurs after $\mathbf{2}$ or $\mathbf{3}$ weeks. Many patients die of infection, both bacterial and fungal, and once infection has occurred it may be exceedingly difficult to treat. Recovery, when it occurs, is sometimes heralded by a transient increase in the blood lymphocyte count, and by lymphocyte infiltration in the marrow (Pisciotta, 1973).

This second type of agranulocytosis is caused by phenothiazines and by tricyclic antidepressants (Miller, 1963; Bird, 1960). Clomipramine is a compound of the dihydrodibenzazepine series and differs from imipramine in the substitution of a chlorine atom in position 2 . The molecular structure of both compounds shows marked similarity to that of the phenothiazine group. Clomipramine was first synthesized in 1958 ana has been widely used as an antidepressant. Since 1966 it has been used intravenously for severe and resistant forms of depression (Collins, 1970), particularly endogenous and involutional types. It has also been used in obsessional and phobic states (Capstick, 1971; Marshall, 1971). In the case described here the agranulocytosis was almost certainly due to clomipramine, and during prolonged administration of this and other tricyclic drugs in high doses it would seem wise to check the white blood count especially if the patient develops fever or a sore throat.

Death from agranulocytosis is due to infection, and fungal infections are not uncommon. In this patient there was severe oral and pharyngeal monilia at the start of the illness, and during the period of agranulo- $\bar{z}$ cytosis there was spreading pulmonary infiltration, $\stackrel{\mathbb{Q}}{\varrho}$ unresponsive to antibiotics, and the sputum con- $c$. tained large amounts of Candida spp. The use of $\vec{F}$ flucytosine in treating systemic Candida infections $\stackrel{5}{?}$ has been reported by Record et al., (1971). They treated three patients with Candida endocarditis in $\frac{\bar{D}}{\bar{D}}$ two of whom the infection was not eradicated. Two patients developed hypoplasia and hepatic necrosis, $\Omega$ probably as a result of treatment. The pulmonary infiltrates in the case described here began to regress $\overrightarrow{0}$ once flucy tosine was started. Abnormal liver function tests were noted during treatment but were not $\vec{\omega}$ necessarily caused by the drug. It is thought that the drug controlled the infection until the time when marrow recovery occurred. Recovery took place in spite of the known toxic effects of the drug on the $\mathrm{N}$ bone marrow.

\section{Acknowledgments}

Dr John Garrod of Roche Pharmaceuticals gave helpful 을 advice about the administration of flucytosine.

\section{References}

BIRD, C.E. (1960) Agranulocytosis due to imipramin̊ (Tofranil). Canadian Medical Association Journal, 28, 102

Brown, P.K. \& Ophuls, W. (1902) A fatal case of acuef primary infectious pharyngitis with extreme leucopenia. American Medicine, 3, 649.

CAPSTICK, N. (1971) Anafranil in obessional states-a follow study. Fifth World Congress of Psychiatry, Mexico.

Collins, G.H. (1970) Intravenous chlorimipramine in the treatment of severe depression. British Journal of Psychiatry, 117, 211.

Crammer, J.L. \& Elkes, A. (1967) Agranulocytosis after desipramine. Lancet, i, 105.

Madison, F.W. \& SQuier, T.L. (1934) The etiology of primary granulocytopenia (agranulocytic angina). Journal of the American Medical Association, 102, 755.

Marshall, W.K. (1971) Treatment of obsessional illnesses and phobic anxiety states with clomipramine. British Journal of Psychiatry, 119, 467.

Miller, M. (1963) Neuropathy, agranulocytosis and hepatotoxicity following imipramine therapy. American Journal of Psychiatry, 120, 185.

Pisciotra, A.V. (1973) Immune and toxic mechanisms in drug-induced agranulocytosis. Seminars in Haematology, 10, No. 4, 279.

Record, C.O., Skinner, J.M., Sleigh, P. \& Speller, D.E.C.E. (1971) Candida endocarditis treated with 5-fluorocytosine. British Medical Journal, 1, 262. 